\title{
$\mathrm{LiNbO}_{3}$ 单晶体中生长区边界处的 界面形态和错配
}

\author{
闵乃本 洪静芬 写 端 \\ （南京大学固体物理研究所）
}

从熔体中生长晶体时固液界面上经常有小面 (facet) 出现, 在小面生长区邻近往往观测到 长程弹性应变场 ${ }^{[2]}$; 溶液生长的晶体中,在不同生长区(锥)交界处也有人观测到类似的现象 ${ }^{[2]}$. 为了探讨这类长程弹性应变场的来源, 我们在直拉法生长的 $\mathrm{LiNbO}_{3}$ 单晶体中, 对小面生长区 边界处的固液界面形态进行了研究,下面简要地报道所得到的初步结果.

\section{实 方 法}

为了揭示生长过程中固液界面的形态,我们有意识地使晶体转轴与温场对称轴不一致,并 在配料中掺有 $1 \%$ 的钎,引人了明显的旋转生长层. 这样, 晶体每旋转一周, 就经历了一次温 度起伏，并对应于晶体内由正负电畴区勾画出来的生长层. 我们用浸蚀法显示了晶体中的生 长层,从而追踪了生长过程中固液界面形态的演变.

\section{结果与 讨 论}

小面生长区边界处的界面形态 在 $\mathrm{LiNbO}_{3}$ 单晶体中小面生长区的边界处，我们观 测 到三种类型的生长层的交接, 分别如图 1、图 2 和图 3 所示. 在这些图中有共同性的是, 旋转 生长层具有周期性,其周期对应于旋转一周所需之时间. 旋转引起了温度起伏,处于温度稍高 的半周期内, 生长速帮较低, 生长的晶体较薄; 在温度稍低的半周期内,生长的晶体较厚(示意 图中都以密集点表示).

图 1 表示了在小面区和非小面区的边界处,生长层是连续交接的; 对不同的生长区,在同 一“半周期”内, 所生长的晶体的厚度相等. 这表明了小面与非小面的显微生长速率的起伏具

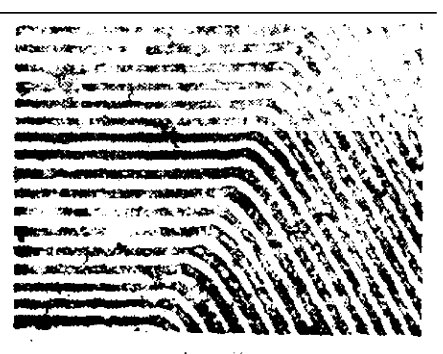

Litituxas

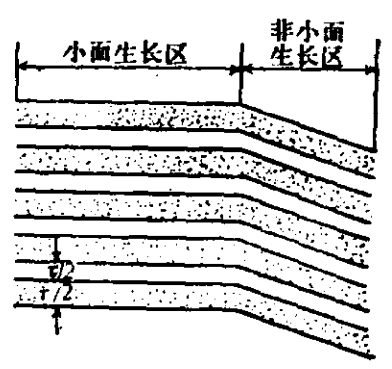

图 1 生长区边界外生长层的连续交接 

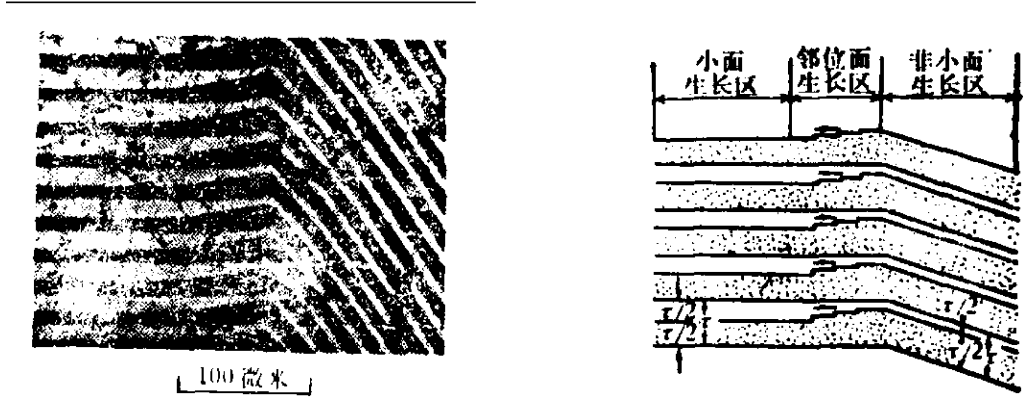

图 2 生长层的“斜坡”交接
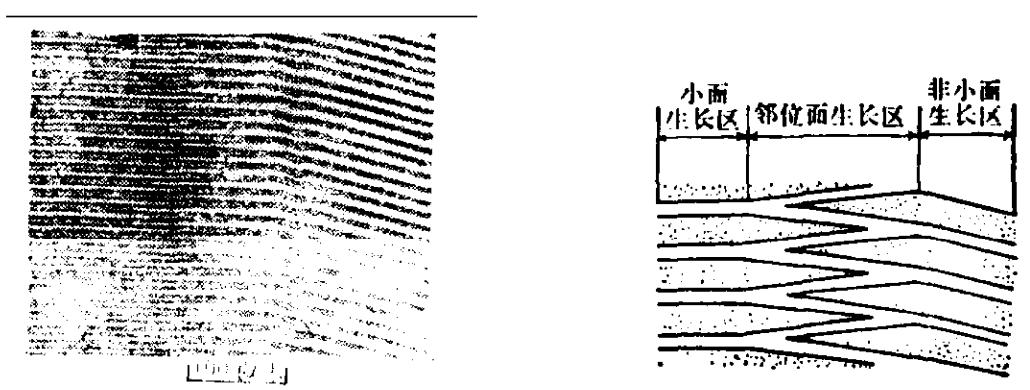

图 3 生长层的“Y” 型交接

有周期相等、振幅相等和周相相同的特征. 在图 2 中, 生长区边界处的生长层的交接虽然仍为 连续的, 但在同一半周期内, 所长成的晶体的厚度不等, 这表明了不同生长区内显微生长速率 关于温度起伏的响应是周期相等、周相相等但振幅不等, 非小面生长区内的生长速率起伏的振 幅较大。在交接处出现了“斜坡”, 这可用 Bunn 等在研究溶液生长时提出的台阶翻越效应 ${ }^{[3]}$ 来 解释,也就是在非小面生长速率较大的前半周期内,在生长区边界处不断有台阶由非小面区翻 越到小面区,引起了邻位面的生长. 图 3 显示了生长区边界处生长层的“ “型交接, 这反映了 两个生长区的显微生长速率是等周期、等振幅, 但周相相反, 参阅图 4. 这不仅在生长区边界 处出现了.邻位面生长区,而且可推测在生长过程中台阶的运动方向是交变的,如图 4 所示.

根据上述的实验事实, 可以得到推论: 小面生长与非小面生长关于温度起伏的动力学响 应是不同的,这正好和 Barthel 等的理论分析所得的结果一致 ${ }^{[4]}$.

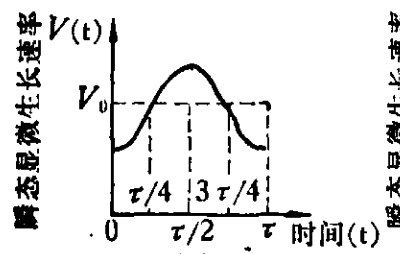

(a)

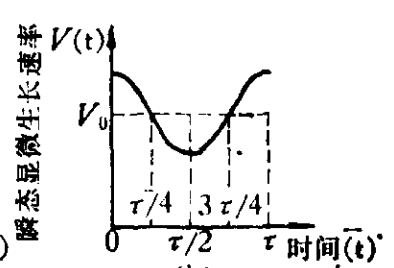

(b)

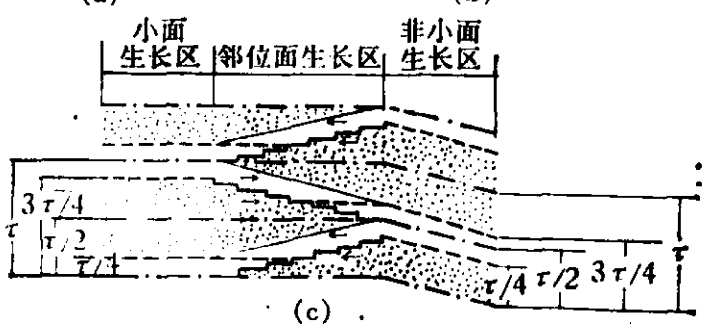

图 4 “ $Y$ ”型交接的形成机制

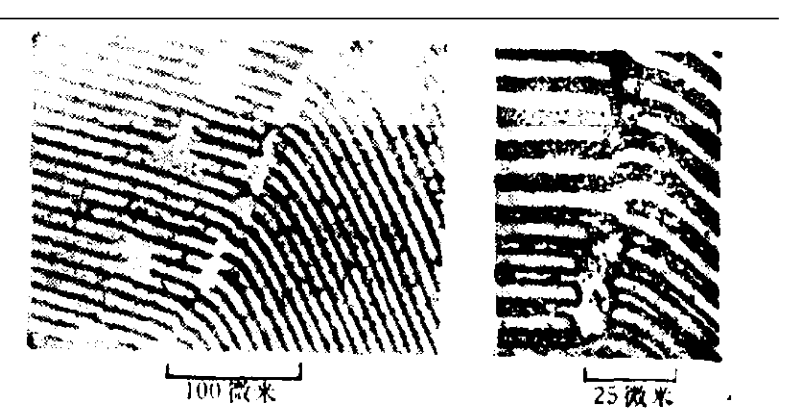

图 5 生长层边界处生长层的错配

(a) 小面生长区的动力学响应; (b) 非小面生长区的 动力学响应: (c) 形成““”交接的交变邻位面生长机制 
生长层间的错配位错 我们研究了生长区边界处生长层的交接, 观察到存在类似于晶 体中的刃型位错的图象, 如图 5 所示. 测量了不同生长区内生长层的间距, 以及生长层与生长 区边界的交角, 借用错配位错理论 ${ }^{[s]}$, 在一例中得到二生长区中生长层的错合度为 $1.5 \%$, 这相 当于每隔 67 层生长层将出现一个“错配位错”, 在量级上与观测结果大体相符. 其误差的来源 是由于晶体中周期性旋转生长层的间距受到功率起伏的调制, 不能严格地保持间距相等.

生长层的间距是微米量级，因而生长层间错配位错, 其尺度比通常晶体中的位错的尺度约 大 4 个量级。这种错配位错和生长区边界处长程应变场的关系有待进一步探讨.

生长区边界处出现亚宏观位错的事实表明，小面生长与非小面生长的生长速率起伏的周 期存在微小差异, 这种差异的来源可能是不同生长区的溶质分凝的差异的累积效应. 这种亚 宏观位错也可能正是 Nye 和 Berry 所提出的波列中的位错的一个特例 ${ }^{[6]}$, 对这一问题我们正在 进一步的研究.

致谢: 本工作从一开始就得到钱临照教授的关伓和鼓励,作者深为感谢。

\section{今 考文献}

[1] 闵乃本、杨永顼。物理学报,28(1979),285.

[ 2$]$ Kito, I. \& Kato, N., J. Crystal Growth, 24/25(1974), 544.

[3] Bunn, C. W. \& Emmett, H., in Crystal Growth, Butterworths, 1959, 119.

[ 4 ] Barthel, J. \& Jurisch, M., J. Crystal Growth, 11(1971), 293.

[ 5 ] Van der Merwe, J. H., in Crystal Growth and Characterization. (eds. Ueda, R. \& Mullin, J. B.), North-Holland, 1975, 175.

[6] Nye, J. F. \& Berry, M. V., Proc. Roy. Soc., A336(1974). 165: 